\title{
EFEITO DA RAPAMICINA SOBRE A APOPTOSE EM CULTURA DE LINFÓCITOS HUMANOS PERIFÉRICOS
}

\author{
Evaluation of Apoptosis in Peripheral Human Lymphocytes Exposed to Rapamycin
}

Taísa Aozani Prochnow', Virna Nowotny Carpio', Esther Cristina Aquino Dias', Roberto Ceratti Manfro², Luiz Felipe Santos Gonçalves²

\begin{abstract}
RESUMO
Objetivo: avaliar a indução de apoptose pela rapamicina em linfócitos humanos periféricos. Métodos: Polimorfos mononucleares foram separados do sangue periférico de voluntários sadios através de centrifugação em gradiente de densidade. A fração mononuclear foi suspensa em meio de cultura, e após, transferida para placas de cultura, às quais acrescentou-se fito-hemaglutinina (PHA) e/ou rapamicina conforme 0 ensaio. Foram testados quatro ensaios experimentais: cultura de linfócitos puros, linfócitos com PHA, linfócitos com rapamicina, e linfócitos com PH A e rapamicina. A s culturas foram incubadas a $37^{\circ} \mathrm{C}$ em atmosfera estéril, com $5 \%$ de $\mathrm{CO} 2$ por 24 e 48 horas. A apoptose foi determinada através da marcação com A nexina $V$ por citometria de fluxo. Resultados: não houve diferença estatisticamente significativa na detecção de apoptose em linfócitos com e sem rapamicina, tanto na análise após $24 \mathrm{~h}(7,1 \%+3,8 \times 6,6 \%+2,6, p=1,0)$ como após $48 \mathrm{~h}$ $(6,1 \%+1,9 \times 6,2+1,8, p=1,0)$. Já, linfócitos com PH A, na presença ou ausência da droga, aumentou estatisticamente a apoptose, tanto nas análises de $24 \mathrm{~h}$ como nas de $48 \mathrm{~h}(\mathrm{P}=0,0000$ e $\mathrm{P}=0,0006$, A N OVA ). Nas culturas estimuladas com PHA a adição de rapamicina também não ocasionou aumento estatisticamente significativo nos percentuais de apoptose tanto em $24 \mathrm{~h}(P=0,69)$ como após $48 \mathrm{~h}(P>0,73)$. Condusão: $0 \mathrm{~s}$ achados deste estudo mostram que a rapamicina não induz apoptose em cultura de linfócitos estimulada ou não.
\end{abstract}

Descritores: rapamicina, apoptose, linfócitos e imunossupressão

\footnotetext{
Grau acadêmico:

1. Mestre em Nefrologia, Faculdade de Medicina, Universidade Federal do Rio Grande do Sul, Porto Alegre RS.

2. Professor Adjunto do departamento de Medicina Interna, Faculdade de Medicina, UFRGS
}

Instituição:

Programa de Pós-Graduação em Ciências Médicas: Nefrologia, Faculdade de Medicina; Universidade Federal do Rio Grande do Sul. Serviço de Nefrologia, Hospital de Clínicas de Porto Alegre. Porto Alegre RS. Brasil.

\section{Correspondência;}

Prof. Dr. Luiz Felipe Santos Gonçalves

Hospital de Clínicas de Porto Alegre - Serviço de Nefrologia

Ramiro Barcelos, 2350, sala 2030 - Porto Alegre, RS, Brasil. 90035-003

Telefone: $555121018295 \quad$ Fax: 555121018121

E-mail:Ifgoncalves@hcpa.ufrgs.br

\section{INTRODUÇÃO}

0 transplante renal é, atual mente, a mel hor opção de tratamento para a insuficiência renal crônica terminal. ${ }^{1}$ Os avanços na compreensão da imunologia dos transplantes e o desenvolvimento de drogas imunossupressoras mais efetivas e eficazes diminuíram a incidência de rejeição aguda para menos de $20 \%$, com mel horas nas sobrevidas de enxertos e pacientes. ${ }^{2}$

A rapamicina, imunossupressor mais recentemente aprovado para uso clínico, é um antibiótico macrolídeo isolado do fungo Streptomyces hygroscopicus. A sua ação imunossupressora depende de sua ligação na imunofilina $\mathrm{FK} \mathrm{BP} \mathrm{P}^{12}$, formando 0 complexo ativo Rapa/FK BP, queinibea atividadeenzimática da mTOR (mammalian target of rapamicin), enzima responsável pelo controle da atividade enzimática de diversas proteínas envolvidas na transdução de sinais de ativação e proliferação derivados de receptores da membrana de linfócitos. ${ }^{3,4} \mathrm{As}$ rapamicinas (sirolimus e everolimus) inibem 0 ciclo celular na transição da fase G1 para S em diversas linhagens celulares, incluindo células musculares lisas (alvo secundário de seu possível ef eito na nefropatia crônica do enxerto) e os linfócitos (alvo primário de seu efeito imunossupressor). ${ }^{5,6}$ Sua eficácia na prevenção da rejeição aguda tem sido demonstrada em al guns estudos clínicos de fase III 7,8 mas apresenta um potencial emprego em esquemas com reti rada precoce de inibidores da calcineurina e possíveis efeitos na prevenção da nef ropatia crônica do enxerto. ${ }^{9}$ 
A apoptose éum processo natural de morte celular, no qual as células se inativam e degradam sua própria estrutura e componentes, de manei ra coordenada e característica. ${ }^{10,11} \mathrm{~N}$ o contexto do transplante de órgãos, a indução de apoptose tem sido documentada como um mecanismo que leva à deleção de linfócitos aloreativos durante a resposta imune ao al oenxerto. ${ }^{12} \mathrm{~A}$ influência dos imunossupressores na regulação da apoptose de linfócitos ativados e seu papel no controle da resposta imune aos aloenxertos humanos ainda não estão bem elucidados. Um estudo real izado in vitro, analisou vários imunossupressores quanto à indução de apoptose em células T humanas. ${ }^{13} 0$ s achados deste estudo sugerem que a rapamicina não induz apoptose em células T ativadas, mas inibe a proliferação e a expansão destas após contato com o antígeno, indicando que as células T são silenciadas e não deletadas. ${ }^{13}$

Por outro lado, estudos experimentais in vivo têm demonstrado a indução de apoptose pela rapamicina. ${ }^{14} \mathrm{Em}$ face das controvérsias a respeito do efeito da rapamicina sobre a indução de apoptose, 0 presente estudo teve como objetivo avaliar este possível efeito da rapamicina em linfócitos humanos periféricos.

\section{MATERIAIS E MÉTODOS Imunossupressor e reagentes}

$N$ as culturas celulares foram utilizados os seguintes reagentes: R PM I-1640 com Hepes (Sigma, St Louis, EUA), soro bovino fetal (Sigma, St L ouis, EUA), penicilina-estreptomicina (G ibco, Paisley, UK) e fito-hemaglutinina (PHA) a $1 \%$ (Sigma, St Louis, EUA). 0 imunossupressor testado foi a rapamicina, na concentração de $10 \mathrm{ng} / \mathrm{mL}$.

\section{Preparações celulares e cultura}

Polimorfos mononucleares foram separados do sangue periférico de voluntários sadios através de centrifugação em gradiente de densidade (Lymphoprep, O slo, N orway). A fração mononuclear foi lavada e suspensa em R PM I-1640 com 10\% de soro bovino fetal e $1 \%$ de antibióticos (penicilina e estreptomicina). As preparações celulares foram transferidas para placas de cultura de 24 poços, com número de células ajustado para $1,5 \times 106$ células $/ \mathrm{mL}$, às quais acrescentou-se PHA e/ou rapamicina, conforme 0 ensaio. Foram testados quatro ensaios experimentais: a) cultura de linfócitos não estimulados; b) cultura de linfócitos estimulados pela PHA; c) cultura de linfócitos não esti mulados e expostos à $10 \mathrm{ng} / \mathrm{mL}$ de rapamicina; d) cultura de linfócitos estimulados pela PHA e expostas à $10 \mathrm{ng} / \mathrm{mL}$ de rapamicina. A s culturas foram incubadas a $37^{\circ} \mathrm{C}$ em atmosfera estéril, com $5 \%$ de $\mathrm{CO} 2$ por 24 e 48 horas. Os ensaios foram realizados em triplicata.

\section{Detecção de Apoptose}

A apoptose foi determinada nos períodos de 24 e $48 \mathrm{~h}$ através da marcação com A nexina $V$ por citometria de fluxo, utilizando-se o kit A nnexin V-EGFP A poptosis Detection (A lexis Biochemicals, Lausen, Switzerland), no aparel ho FACScan (Becton Dickinson, Heidelberg, G ermany), utilizando-se o sof tware CellQuest para a análise dos dados. A anexina $V$ liga-se à fosfatidilserina exposta na superfície celular nas fases iniciais do processo apoptótico. A s células coradas pela anexina $\mathrm{V}$, mas não pelo iodeto de propídeo, foram interpretadas como entrando em apoptose.

\section{Análise estatística}

Os valores percentuais de linfócitos apoptóticos em cada um dos quatro ensaios experimentais foram avaliados estatisticamente pela A nál ise de V ariância Simples, seguida pelo Teste de Scheff. 0 nível de significância estabelecido foi $p<0,05$.

\section{RESULTADOS}

A figura 1 ilustra os resultados obtidos dos quatro ensaios experimentais (cultura de linfócitos não estimulados, linfócitos estimulados pela $\mathrm{PH}$ A, linfócitos expostos à rapamicina, elinfócitos estimulados e expostos à rapamicina), nos períodos de 24 e $48 \mathrm{~h}$.

Figura 1 - Percentual de apoptose em linfócitos periféricos humanos não estimulados, estimulados por PHA, expostos à rapamicina, e estimulados e expostos à rapamicina. Período de 24 horas (barras vazias) e 48 horas (barras cheias)

$\%$ APOPTOSE

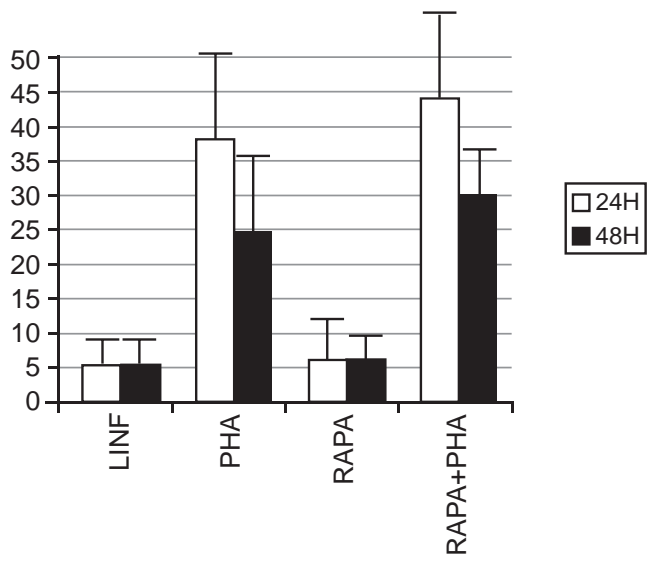

Verifica-se que não houve diferença estatisticamente significativa na detecção de apoptose nas culturas de linfócitos com e sem rapamicina, tanto na análise de $24 \mathrm{~h}(7,1 \%+3,8 \times 6,6 \%+2,6$, $\mathrm{p}=1,0)$ como após $48 \mathrm{~h}(6,1 \%+1,9 \times 6,2+1,8, p=1,0)$.

No entanto, quando se estimularam as culturas de linfócitos com PHA, na presença ou ausência da droga, houve aumento estatísticamente significativo da apoptose, em comparação com os demais grupos, tanto nas análises de 24 como nas de $48 \mathrm{~h}$ $(P=0,0000$ e $P=0,0006$, AN OVA $)$.

Quando se avaliou a adição de rapamicina às culturas estimuladas por PHA verificou-se que esta induziu um discreto aumento no percentual de linfócitos em apoptose, embora sem atingir diferença estatisticamente significativa, tanto na análise dos ensaios em $24 \mathrm{~h}$ $(46,55 \%+11,0 \times 39,0 \%+12,6, P=0,69)$ como após $48 \mathrm{~h}(30,2 \%$ $+8,7 \times 24,3 \%+11,0, P=0,73)$.

\section{DISCUSSÃO}

A introdução de drogas imunossupressoras mais efetivas e eficazes representou um marco fundamental para 0 avanço do transplante de órgãos nas últimas décadas. Estudos recentes vêm demonstrando que alguns imunossupressores utilizados no transplante renal 
podem induzir apoptose nos linfócitos, diminuindo a produção da IL -2, um potente fator de crescimento dos linfócitos T que estimula a divisão celular e expansão clonal das células auxiliares e citotóxicas antígeno-estimuladas. ${ }^{15,16} \mathrm{No}$ entanto, o papel dos imunossupressores na regulação da apoptose de linfócitos ativados ainda não está bem elucidado.

No presente estudo, avaliamos a indução de apoptose in vitro do imunossupressor rapamicina em cultura de linfócitos humanos periféricos, nos períodos de $24 \mathrm{~h}$ e $48 \mathrm{~h}$. Testamos quatro ensaios experimentais: a) linfócitos não estimulados, b) linfócitos estimulados pela PH A, c) linfócitos expostos à rapamicina, e d) linfócitos estimulados e expostos à rapamicina.

A análise dos resultados dos nossos ensaios mostrou que quando estimulamos as culturas com PHA, na presença ou ausência da droga, houve aumento estatisticamente significativo da apoptose, em comparação com os grupos não estimulados, tanto nas análises de $24 \mathrm{~h}$ como após 48h. Da mesma forma, outros autores estudando apoptose em cultura de linfócitos $T$ periféricos humanos encontraram aumento da apoptose nas culturas estimuladas com PH A na análise de $18 \mathrm{~h} .{ }^{17} \mathrm{~A}$ PHA é um agente mitogênico para linfócitos humanos que age fundamental mente sobre os linfócitos $T .18$

Em nosso estudo, quando acrescentamos a rapamicina $(10 \mathrm{ng} / \mathrm{mL})$ nas culturas de linfócitos com PHA, e na ausência desta, não encontramos diferença estatisticamente significativa na detecção de apoptose tanto na anál ise de $24 \mathrm{~h}$ como após $48 \mathrm{~h}$. 0 utros estudos mostram que a rapamicina não induz apoptose em cultura de células T de hibridomas (D0.11.10 cel) na análise de 16 h. ${ }^{19}$ Igualmente, outros autores também não encontraram indução de apoptose, em culturas de células T imaturas de camundongos, quando estas foram expostas a concentrações de $10 \mathrm{pg} / \mathrm{mL}-100 \mathrm{ng} / \mathrm{mL}$ de rapamicina, em análise de 48 h. ${ }^{20}$ Também já foi estudada a indução de apoptose em culturas de células $T$ periféricas humanas expostas a vários imunossupressores. ${ }^{13}$ Seus achados sugerem que a rapamicina, mesmo em altas concentrações, não induz à apoptose aquelas células. No entanto, um estudo realizado em cultura mista de linfócitos mostrou que a rapamicina aumenta a apoptose de células T CD 4+, quando comparada com a ciclosporina ou FK $506 .{ }^{21} \mathrm{Da}$ mesma forma, um estudo realizado em cultura de células $B$ de linfoma mostrou que a rapamicina induz à morte estas células através da indução de apoptose. ${ }^{22}$ Tais diferenças entre os estudos poderiam ser explicadas pelos diferentes tipos celulares anal isados e diferentes métodos de detecção de apoptose empregados.

Existem diversos métodos para qual ificar ou quantificar apoptose; a maioria deles detectam alterações nucleares que ocorrem nas células durante o processo, como diminuição de tamanho, condensação da cromatina e fragmentação do DNA. ${ }^{23}$ N osso estudo utilizou como método de quantificação de apoptose a detecção por citometria de fluxo de anexina $\mathrm{V}$, uma proteína que se liga à fosfatidilserina externalizada na membrana celular nas fases iniciais da apoptose. Portanto, a anexina $V$ é um marcador precoce, ideal para os ensaios analisados em $24 \mathrm{~h}$ e após $48 \mathrm{~h}$. O utros métodos de avaliação de apoptose, como a fragmentação do DNA, são marcadores tardios de apoptose.

A apoptose nas células tubulares renais tem sido estudada como um possível indicador da viabilidade do enxerto e da extensão da lesão de isquemia-reperfusão que ocorre após o transplante renal. Esta hipótese é confirmada por um estudo que mostrou redução no grau de apoptose das células tubulares em rins de transplantados com função inicial do enxerto. ${ }^{24}$ Outro autor atribui ao uso de rapamicina a piora da recuperação da insuficiência renal aguda induzida em camundongos por oclusão da artéria renal. ${ }^{25}$ Segundo este autor, esta droga aumentaria a morte de células tubulares (via apoptose) e inibiria a resposta regenerativa destas células.

Embora tais achados tivessem sido estudados em modelo experimental in vivo e se relacionassem à indução de apoptose em células tubulares, eles são discrepantes em relação aos nossos achados in vitro e à maioria dos estudos semel hantes, que não mostram indução de apoptose pela rapamicina. ${ }^{19,} 20,21$

A indução de apoptose em linfócitos no contexto da transplantação deórgãos pode estar relacionada ao controle do processo de rejeição aguda mediante a deleção de linfócitos aloreativos e também mais tardiamente, por este mesmo mecanismo, influenciando o desenvolvimento de tolerância imunológica. ${ }^{26} \mathrm{Em}$ estudo experimental empregando transplante de pele em ratos, foi mostrado que a rapamicina induz tolerância através da apoptose de células $\mathrm{T}$ aloreativas. ${ }^{27} \mathrm{O}$ utros estudos sugerem que a rapamicina atua no desenvolvimento de tolerância periférica através da indução de anergia por inibição da transdução dos sinais mediados pela IL -2. ${ }^{28}$ Nossos achados, in vitro, de ausência de indução de apoptose suportam a hipótese de indução de anergia como provável mecanismo de indução de tolerância pela rapamicina.

\section{CONCLUSÃO}

Os achados deste estudo mostram que a rapamicina não induz apoptose em cultura de linfócitos T, estimulada ou não. Portanto, é mais provável que seu mecanismo de ação não seja a deleção de linfócitos ativados, mas a inibição da proliferação destas células, o que contribui ria para a prevenção da rejeição aguda e talvez para a indução de anergia.

\section{ABSTRACT}

The influence of immunosuppressant drugs in regulating the activated lymphocytes and their role in controlling the immune response to human al lografts is still yet to be determined. The aim of this study was to evaluate the induction of apoptosis by rapamycin in peripheral human lymphocyte. Methods: M ononuclear polymorphs were obtained from blood of healthy donors. Isolation was performed by Lymphoprep. Cells were cultured for 24 and $48 \mathrm{~h}$ on 24 phytohemagglutinin-coated (PHA) well plates and/or rapamycin, as specified to the test. Four experimental culture tests were performed: non-stimulated lymphocytes, stimulated by PHA lymphocytes, non-stimulated lymphocytes, exposed to rapamycin and stimulated by PH A lymphocytes, and lymphocytes exposed to rapamycin. A poptosis was determined 
by A nnexin V-EGFP staining to externalized phosphatidyllserine on FACScan cytometer. Results: There was no statistically significant difference in the apoptosis detection in lymphocyte cultures with and without rapamycin both in $24 \mathrm{~h}(7,1 \%+3,8 \times 6,6 \%+2,6, p=1,0)$ and after $48 \mathrm{~h}(6,1 \%+1,9 \times 6,2+1,8, p=1,0)$. However whenever the lymphocytes cultures were PHA-stimulated in the presence or absence of rapamycin, there was a statistically significant increase in the apoptosis in $24 \mathrm{~h}$ and $48 \mathrm{~h}$. The addition of rapamycin to PH A stimulated cultures did not signicantly increase the percentage of lymphocyte apoptosis either after $24 \mathrm{~h}(P=0.69)$, and after $48 \mathrm{~h}(\mathrm{P}=0.73)$. Condusion: These data suggest that rapamycin does not induce apoptosis in a lymphocytes culture whether stimulated or not with PH A.

Keywords: rapamycin, apoptosis, lymphocytes, immunossupressant.

\section{REFERÊNCIAS}

1. Cecka JM. The UNOS Scientific Renal Transplant Registry. Clin Transplant 1999; 165: $1-12$.

2. Hariharan S, Jonhson CP, Bresnahan BA, Taranto SE, Mcintosh MJ, Stablei D Improved graft survival after renal transplantation in The United States, 1988 to 1996. N Engl J Med 2000; 342: 605-12.

3. Sabatini DM, Barrow RK, Blackshaw S, Burnett PE, Lai MM, Field ME, et al Interaction of RAFT1 with gephyrin required for rapamycin-sensitive signaling. Science $1999 ; 284$ : 1161-4.

4. Abraham T, Wiederrecht GJ. Immunopharmacology of rapamycin. Annu Rev Immunol 1996; 14: 483-510

5. Kim HS, Raskova J, Degiannis D, Raska K Jr. Effects of cyclosporine and rapamycin on immunoglobulin production by preactivated human B cell. Clin Exp Immunol 1994; 96: 508-12

6. Cao W, Mohacsi P, Shorthouse R, Pratt R, Morris RE. Effect of rapamycin on growth factor-stimulated vascular smooth muscle cell DNA synthesis. Inhibition of basic fibroblast growth factor and platelet-derived growth factor action and antagonism of rapamycin by FK506. Transplantation 1995; 59 (a): 390-5.

7. Kahan BD. Efficacy of sirolimus compared with azathioprine for reduction of acute renal allograft rejection: a randomised multicentre study. The Rapamune US Study Group. Lancet 2000; 356: 194-202.

8. MacDonald AS, RAPAMUNE Global Study Group. A worldwide, phase III, randomized, controlled, safety and efficacy study of a sirolimus/cyclosporine regimen for prevention of acute rejection in recipients of primary mismatched renal allografts. Transplantation 2001; 71: 271-280

9. Johnson RW, Kreis H, Oberbauer R, Brattstrom C, Claesson K, Eris J. Sirolimus allows early cyclosporine withdrawal in renal transplantation resulting in improved renal function and lower blood pressure. Transplantation 2001; 72: 777-786.

10. Sánchez EL, Vargas FD. Apoptosis: the phenomenon and its determination. Téc Pecu Mex 2003; 41: 49-62.

11. Hengartner MO. The biochemistry of apoptosis. Nature 2000; 407: 770-776

12. August C, Schmid KW, Dietl KH, Heidenreich S. Prognostic value of lymphocyte apoptosis in acute rejection of renal allograft. Transplantation1999; 67: 581-585.

13. Stauss G, Osen W, Debatin KM. Induction of apoptosis and modulation of activation and effector function in T cells by immunosuppressive drugs. Clin Exp Immunol 2002; 128: 255-266.

14. Lutz J, Zou H, Liu S, Antus B, Heemann. Apoptosis and treatment of chronic allograft nephropathy with everolimus. Transplantation 2003; 76: 508-515.
15. Suthantiran M, Morris RE, Strom TB. Immunosuppressants: cellular and molecular mechanisms of action. A J Kidney Dis 1996; 28: 159-172.

16. Di Renzo M, Capecchi PL, Camurri A, Di Ciolla F, Maccherini M, Lisi G, et al Enhanced apoptosis of peripheral blood mononuclear cells in cardiac transplanted patients undergoing chronic immunosuppressive treatment. Transplant Immunology 2002; 10: 269-275

17. Wu MX, Ao Z, Daley JF, Scholossman SF. Induction and detection of apoptosis in human periphery blood T cell. J Im Methods 1997; 206: 153-162.

18. Olej B, Lugon JR, P da Silva FE, Meletti-Oliveira MC, Rumjanek VM. Atividade imunossupressora de preparações de ciclosporina A em células mononucleares. J Bras Nefrol 2002; 24 (Supl 1): 5-10.

19. Staruch MJ, Sigal NH, Dumont FJ. Differential effects of the immunosuppressive macrolides FK-506 and rapamycin on activation-induced T-cell apoptosis. Int $\mathbf{J}$ Immunopharmac 1991; 13: 677-685.

20. Ishizuka T, Sakata N, Johnson GL, Gelfand EW, Terada N. Rapamycin potentiates dexamethasone- induced apoptosis and inhibits JNK activity in lymphoblastoid cells. Biochemical and Biophysical Research Communications1997; 230: 386-391.

21. Koenen HJ, Michielsen EC, Verstappen J, Fasse E , Joosten I. Superior T-cell suppression by rapamycin and FK506 over rapamycin and cyclosporine a because of abrogated cytotoxic T-lymphocyte induction, impaired memory responses, and persistent apoptosis. Transplantation 2003; 75: 1581-1590.

22. Muthukkumar S, Ramesh TM, Bondada S. Rapamycin, a potent immunosuppressive drug, causes programmed cell deth in B lymphoma cells. Transplantation 1995; 60: 264-270.

23. Bauer KD, Duque RE, Shankey TV. In: Clinical Flow Cytometry Principles and Application. Part 1- Section B. Technical Aspects. Library of Congress, 1993.p 71-1777.

24. Toronyi E, Lord R, Bown ID, Perner F, Szende B. Renal tubular cell necrosis and apoptosis in transplanted kidneys. Cell Biology Int 2001; 25: 267-270.

25. Lieberthal W, Levine JS. Mechanisms of apoptosis and its potential role in tubular epithelial cell injury. Am J Physiol 1996; 271: 477-488.

26. Wells AD, Li XC, Li Y, Walsh MC, Zheng XX, Wu Z, et al. Requirement for T-cell apoptosis in the induction of peripheral transplantation tolerance. Nature Medicine 1999; 5: 1303-1307.

27. Li Y, Li XC, Zheng XX, Wells AD, Turka LA, Strom TB. Blocking both signal 1 and 2 of T-cell activation prevents apoptosis of active $\mathrm{T}$ cell and induction of peripheral allograft tolerance. Nature Medicine1999; 5: 1298-1302.

28. Prud'homme GJ, Vanier LE, Bocarro DC, Ste-Croix H. Effects of cyclosporine A, rapamycin, and FK520 on peripheral T-cell deletion and anergy. Cellular Immunology 1995; 164: 47-56 